\title{
Differentiation and Genetic Analysis of Rhodnius prolixus and Rhodnius colombiensis by rDNA and RAPD Amplification
}

\author{
Carlos Jaramillo, María Fernanda Montaña, Lyda Raquel Castro, \\ Gustavo A Vallejo*, Felipe Guhl/ ${ }^{+}$
}

\begin{abstract}
Centro de Investigaciones en Parasitología Tropical, Departamento de Ciencias Biológicas, Universidad de los Andes, Apartado Aereo 4976, Bogotá, Colombia *Laboratorio de Parasitología, Departamento de Biología,

Facultad de Ciencias, Universidad del Tolima, Ibagué, Colombia
\end{abstract}

\begin{abstract}
Domiciliated Rhodnius prolixus and sylvatic R. colombiensis were analyzed in order to confirm their genetic divergence and verify the risk that the latter represents in the domiciliation process, and to provide tools for identifying the sources of possible reinfestation by triatomines in human dwellings allowing control programs to be undertaken. Comparison of random amplified polymorphic DNA amplification patterns and cluster analysis suggests reproductive discontinuity between the two species. The calculated statistical $F$ value of 0.24 and effective migration rate of 0.6 individuals per generation are insufficient to maintain genetic homogeneity between them and confirm the absence of present genetic flow. R. colombiensis presents higher intrapopulation variability. Polymerase chain reaction of ribosomal DNA supports these findings. The low genetic flow between the two species implies that $\mathrm{R}$. colombiensis do not represent an epidemiological risk for the domiciliary transmission of Trypanosoma cruzi in the Tolima Department. The lower variability of the domiciliated R. prolixus could result in greater susceptibility to the use of pesticides in control programs.
\end{abstract}

Key words: Rhodnius prolixus - Rhodnius colombiensis - domiciliated and sylvatic triatomines - molecular markers - random amplified polymorphic DNA - ribosomal genes - control programs

Rhodnius prolixus (Stal, 1859) is the main vector of Trypanosoma cruzi, the causative agent of Chagas disease in many countries of South and Central America. This disease affects around 11 million people in the region (Schmunis 1994). In Colombia, $3.3 \%$ of the population are infected and $10 \%$ are at risk of acquiring the infection. Although more than 20 different species of triatomines have been described harboring $T$. cruzi in the country, $R$. prolixus is by far the most important vector responsible for transmission (Guhl \& Schofield 1996).

The social and economic impact of Chagas disease is high. It is estimated that the burden of the disease in Latin America is higher than malaria, schistosomiasis and leishmaniasis. The disease is ranked as the fourth cause of mortality in Latin America (Schmunis 1994).

This research was supported by UNDP/World Bank/ WHO Special Programme for Research and Training in Tropical Diseases.

${ }^{+}$Corresponding author. Fax: +57-1-3324540. E-mail: fguhl@uniandes.edu.co

Received 19 May 2000

Accepted 6 August 2001
The most effective control measures against the disease involves interruption of vectorial and transfusional transmission of the parasite. In order to achieve this goal the Southern Cone countries in Latin America designed and developed strategies for domiciliated vector control programs based on the eradication of the insects from dwellings by spraying with residual insecticides. In Colombia triatomines occurs both in sylvatic and domestic habitats and reinfestation of treated households by wild triatomines could be a problem. Thus, entomological studies that allow the origin of reinfesting insects to be identified should be an integral part of control and epidemiological surveillance programs.

The presence of sylvatic triatomines in the country has been reported by several authors on palm trees, mainly Attalea butyracea in Tolima Department (Susunaga et al. 1991, López \& Moreno 1995). These specimenes were reported previously as sylvatic Tolima population by Dujardin et al. (1999) and were clearly differentiated by isoenzymes methods from other species within the genus Rhodnius. Furthermore, Moreno et al. (1999) described the sylvatic individuals as $R$. colombiensis. The present study intends to confirm the genetic divergence between both species. Thirty two individuals of 
each species were selected in order to establish other molecular markers that allow the species to be differentiated, based on a random amplified polymorphic DNA (RAPD) technique that detects genetic polymorphisms and the amplification of ribosomal genes.

\section{MATERIALS AND METHODS}

Insects - A total of 62 individuals of $R$. prolixus were captured inside 10 human dwellings in Coyaima, in the Department of Tolima, where evidence of domiciliation was present; $R$. colombiensis: a total of 62 individuals were captured in sylvatic habitats on 12 palm trees; A. butyracea in a radius between $10 \mathrm{~m}$ to $100 \mathrm{~m}$ from the human dwellings in the same location. $R$. colombiensis specimens were identified according to Moreno et al. (1999).

DNA extraction - To carry out the RAPDs, DNA from 32 domestic and 32 sylvatic individuals was extracted from six macerated legs of each specimen, by consecutive purifications with phenol-chloroform according to Gomes et al. (1998) with some modifications. The samples were washed with hypoclorite before extraction to avoid contact with foraneous DNA. For the PCR-rDNA reactions, DNA was obtained from the legs of the specimens triturated with a hand-held plastic pestle, designed to fit into the base of a standard $1.5 \mu \mathrm{l}$ microfuge tube and using the QIAamp tissue kit from QIAGEN. The DNA extracted was stored at $-70^{\circ} \mathrm{C}$ until use.

DNA quantification - DNA quantification was performed by comparison with samples of known concentration through electrophoresis in $0.8 \%$ agarose gels stained with ethidium bromide and by spectrophotometry with a DyNA Quant, using Hoechst dye 33258.

$R A P D-P C R$ - Five of 25, Operon Kit A 1-20® (OPA) and Ready to go 1-5® (RTG) primers were chosen as they showed polymorphisms of welldefined amplification (1-5 RTG), under the conditions suggested by the manufacturer. Amplification was visualized by electrophoresis in $2 \%$ agarose gels stained with ethidium bromide and 6\% acrylamide stained with silver nitrate according to Sanguinetti et al. (1994).

Phenograms - The genetic information was arranged in a matrix of binary data that were crossed with UPGMA algorithm in order to create phenograms, using Jaccard's dissimilarity index with software Syntax 5.1. Statistical F (Fst) was calculated and the effective migration rate between the two species was estimated using the RAPDBIOS program.

PCR amplification of ribosomal genes - Amplification was done using the GIBCO BRL Taq DNA polymerase recombinant kit using universal prim- ers with specific sequences: ITS1: 3'TCCGTAGGTG AACTGCGG5'; ITS4:3'TCCTCCGCTTATTGATA5'; ITS 5: 3'GGAAGTAAAAGTCGTAACAAGG 5'.

The amount of reagents was based on that found to be optimal for PCR assays ( $25 \mu$ of reaction mixture). Good resolution of the bands was obtained with $5 \mathrm{ng}$ of primer per reaction. Briefly, the following reaction conditions were used: ITS5ITS4 pair of primers: $2 \mathrm{mM}$ of dNTPs, $2.5 \mu \mathrm{l}$ of PCR buffer-10X, $4 \mathrm{mM}$ of magnesium chloride, $0.1 \mu \mathrm{M}$ of each primer, 5 units of ampli-Taq polymerase and $5 \mu \mathrm{l}$ of DNA. ITS1-ITS4 pair of primers: $2 \mathrm{mM}$ of dNTPs, $6 \mathrm{mM}$ of magnesium chloride, $2 \mu$ of PCR buffer-10x, $0.2 \mu \mathrm{M}$ of each primer, 2.5 units of ampliTaq, and $5 \mu$ of DNA. Negative controls using distilled water were used to detect possible contaminations. Amplification was completed using a Perkin Elmer machine with a "touchdown PCR" profile, which allows a reaction within a range of annealing temperatures. Program of 33 cycles of denaturation at $92^{\circ} \mathrm{C}$ for $30 \mathrm{sec}$, annealing at $55^{\circ} \mathrm{C}$ for $30 \mathrm{sec}$ $\left(-0.5^{\circ} \mathrm{C} /\right.$ cycle $)$ and extension at $72^{\circ} \mathrm{C}$ for $40 \mathrm{sec}$ was performed, the entire $25 \mathrm{ml}$ reaction was mixed with $5 \mu \mathrm{l}$ of standard agarose gel loading buffer containing bromophenol blue, and electrophoresed through a $1 \%$. agarose-Tris-Borate-EDTA gel containing ethidium bromide. The amplified PCR fragments were visualized by UV light illumination.

\section{RESULTS}

For the detection of the amplification products, the best resolution was obtained when $6 \%$ acrylamide gels were used. Primer amplification of RAPDPCR markers showed clear banding patterns for each species (Fig. 1). Remarkable differences in patterns between the two species were observed. Comparisons of amplification pattern and cluster analysis suggests reproductive discontinuity between them. The results obtained for each pattern were converted into matrixes of binary data, representing 0 the absence of a fragment and 1 its presence. The analysis was carried out by dividing each gel in horizontal regions, each of which lies between two bands of molecular weight marker (Fig. 1).

Cluster analysis was perfomed calculating Jaccard's dissimilarity index to compare each pair of individuals using the UPGMA algorithm. The first step is a comparison of all the individuals, selection of the two closest, turning them into only one so that they lose their individual identity and can be considered as a single individual. Then this individual is compared with the remaining specimens and forms a new pair with the closest individual. This process can involve many cycles and is repeated for all the individuals until the last cluster pair is unified. Finally, phenograms are constructed. The analysis of them suggests that the two species 


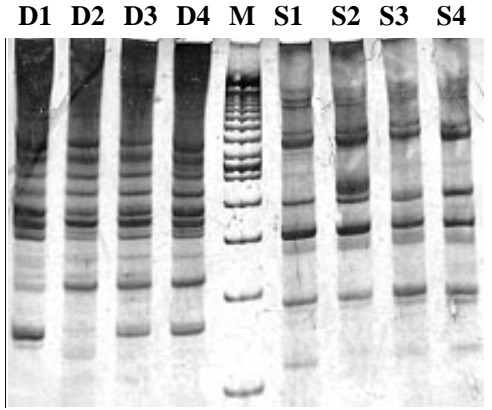

Fig. 1: amplification pattern generated by primer RTG 3 . Polyacrylamide gel $(6 \%)$ dyed with silver nitrate. D1-D4: amplification pattern for Rhodnius prolixus; M: molecular weight marker, 100 bp ladder; S1-S4: amplification pattern for $R$. colombiensis

are effectively reproductively isolated (Fig. 2).

The migration rate between species $(\mathrm{Nm})$ was also estimated in order to evaluate the potential dispersion from one population to the other. To estimate $\mathrm{Nm}$, the Fst was calculated according to Wright (1951).

RAPDs can be used to detect polymorphic loci which segregate as dominant alleles. Consequently, the presence of a band determines the dominant homozygotic in genotype and its absence in the recessive homozygotic genotype. However, there is no information for heterozygotes, so three different ways to calculate Fst were used: Wright's Fst (1951), Weir and Cockerham (1984), Lynch and Milligan (1994). The unknown number was estimated by these three measures, using HardyWeinberg's equilibrium as a hypothesis. The analysis of the polymorphisms generated by RAPDs was undertaken using four assumptions, following Apostol et al. (1993).

The Fst value according to Wright's method was 0.290 , and the migration rate was 0.6 individuals per generation between the two species. Based on Weir and Cockerham's method, Fst was 0.463 and $\mathrm{Nm}$ was 0.3 while according to Lynch and Milligan's method, Fst was 0.446 and $\mathrm{Nm}$ was 0.3 . In all cases the Nm obtained was insufficient to maintain genetic homogeneity between both species.

Fig. 3 shows that applying rDNA-PCR with ITS5ITS4 primers, the domiciliated population amplified a band of $1115 \mathrm{bp}$ and a band of $533 \mathrm{bp}$; the sylvatic population presented as main products 1175 bp and $582 \mathrm{bp}$. Using the ITS1-ITS4 primers, the $R$. prolixus presented a band of $1102 \mathrm{bp}$ and the $R$.

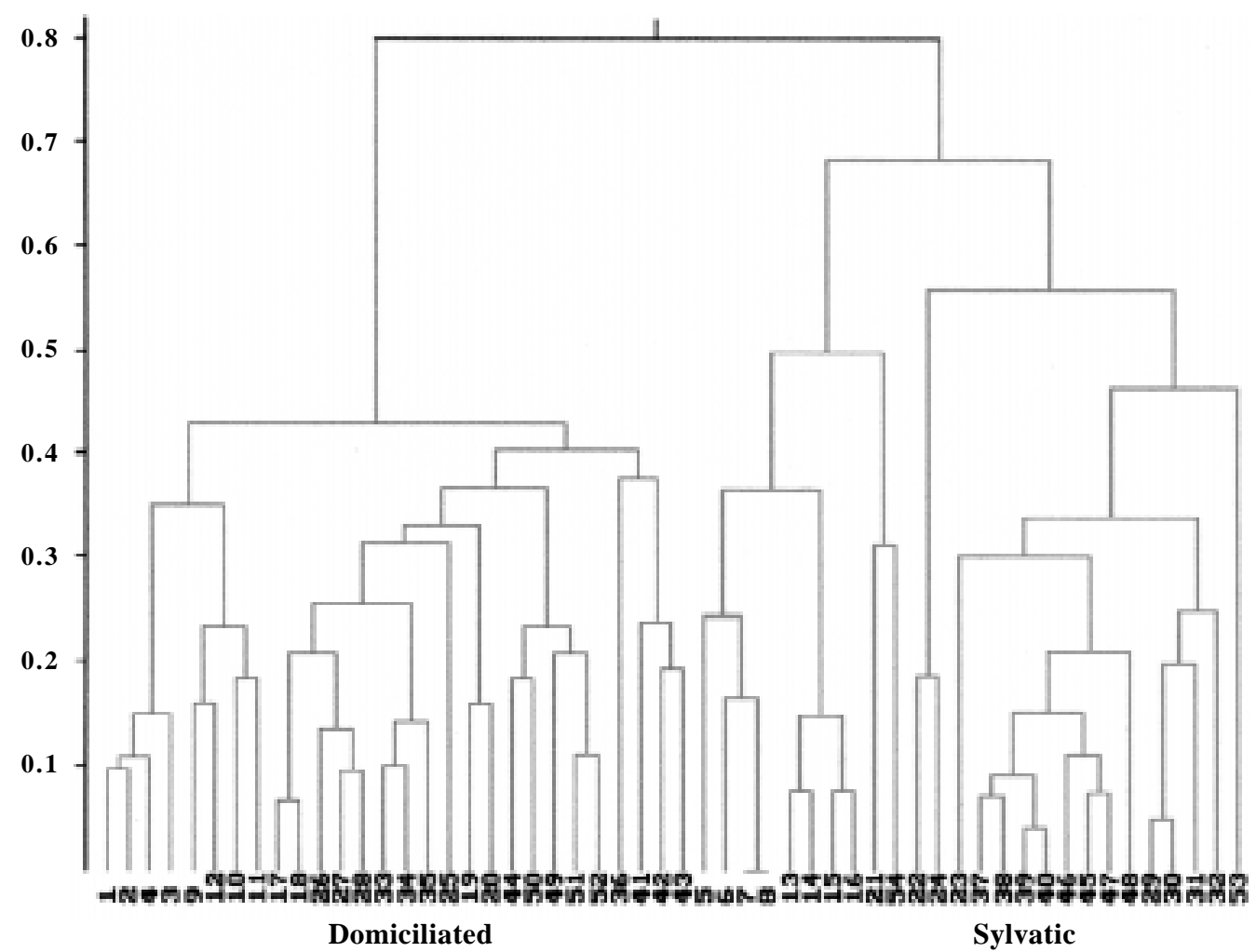

Fig. 2: phenogram generated for sylvatic and domiciliated populations of Rhodnius in Colombia, using Jaccards dissimilarity index and the UPGMA algorithm 
colombiensis a band of $1171 \mathrm{bp}$. Both species evidenciated a band of approximately $556 \mathrm{bp}$ (Figs $3,4)$. The size of the bands was calculated using linear regression. After several reactions, it was found that five units of ampli-Taq polymerase in a $25 \mu \mathrm{l}$ reaction was the appropriate amount to consistently amplify the diagnostic rDNA fragments, using the ITS5-ITS4 primers, and that 2.5 units of Taq were sufficient for the amplification of rDNA, using ITS1-ITS4 primers (Figs 3, 4)

\section{DISCUSSION}

A total of 25 primers were initially evaluated, five of which showed the presence of polymorphisms in the two species. The results show that oligonucleotides RTG 1-5 provide clear amplification patterns that could be used as a basis for analy-

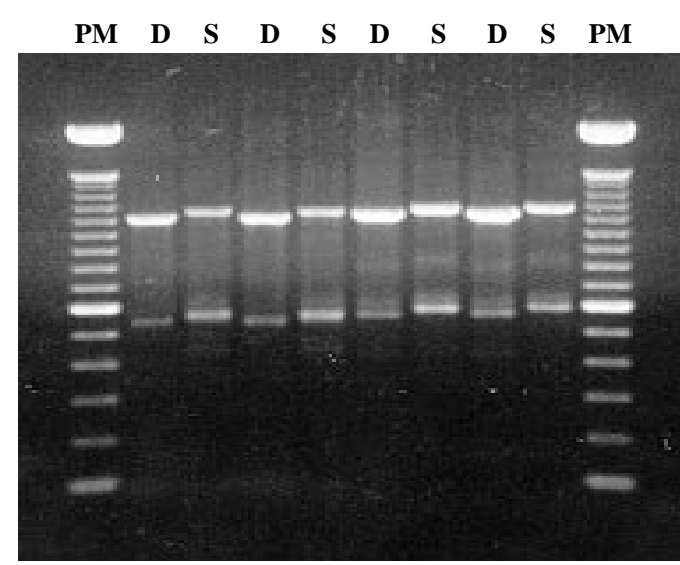

Fig. 3: agarose gel electrophoresis of PCR amplified rDNA gene using ITS1-ITS4 primers, for the first four lanes and primers ITS5-ITS4 for the next lanes. S: sylvatic individual, D: domiciliated individual, $\mathrm{PM}=100 \mathrm{bp}$ molecular weight markers

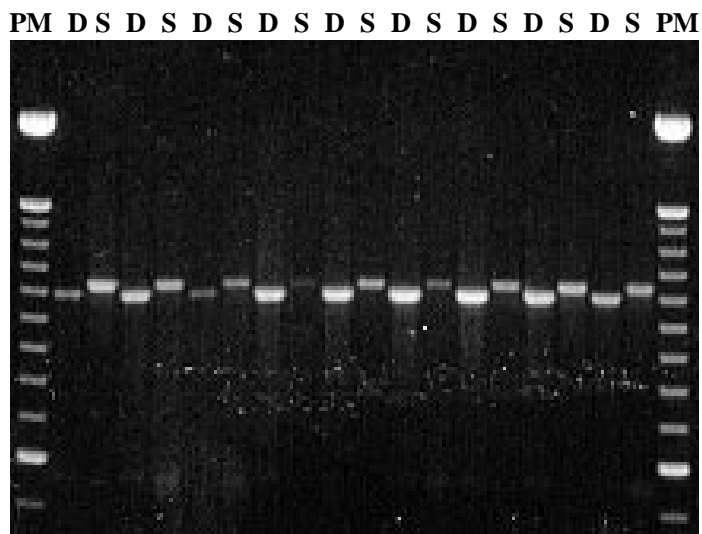

Fig. 4: agarose gel electrophoresis of PCR amplified rDNA gene using ITS1-ITS4 primers. S: sylvatic individual; D: domiciliated individual; PM: 100 bp molecular weight markers sis and comparison of other Rhodnius species. Four mutation types, that can be revealed by RAPD, produced this variability: punctual mutations (e.g. annealing site), inversion in one of the annealing sites, insertion and deletion within the amplified region. Sylvatic populations of most species present a higher variability than conspecific domiciliated populations (Guhl \& Schofield 1996). The results of the present study provide more evidence of this, as $R$. colombiensis is more variable than $R$. prolixus. This can be seen clearly in the phenogram elaborated by using the UPGMA algorithm and the Jaccard's dissimilarity index. The first ramification, grouping all the wild $R$. colombiensis specimens, has a value of 0.7 units, while the branch grouping the domiciliated $R$. prolixus originates around 0.4 units. This low variability is an important clue for the implementations of programs by insecticide spraying, due to the reduced likelihood of resistance to pesticides. In theory, $R$. prolixus, like Triatoma infestans (Klug, 1834) presents a population structure where differences are a matter of the geographic distance between populations (Dujardin et al. 1998). In order to corroborate this interpretation, the effective migration rate $(\mathrm{Nm})$ was calculated using the methodologies of Wright (1951), Weir and Cockerham (1984) and Lynch and Milligan (1994).

The more Fst increases the more differentiates the populations. Negative values for Fst due to surrounding errors in the calculations can be interpreted as Fst equal to zero (Long 1986). The values obtained for $\mathrm{Nm}$ show the approximate number of individuals migrating from one population to the other, in a typical island model. The calculated average value for Fst in the studied populations was 0.029 . It can be concluded that the average effective migration rate is 0.6 individuals per generation, insufficient to maintain both populations as genetically homogeneous. Nm and Fst values can be interpreted in terms of other published values (Bossart $\&$ Scriber 1995). Apostol et al. (1993) reported an $\mathrm{Nm}=11.7$ for Aedes aegypti (the main vector of the yellow fever and dengue arboviruses) in Puerto Rico and Bossart and Scriber (1995) reported an average $\mathrm{Nm}=-0.0032$ for the butterfly Papilo glaucus in Ohio, Georgia and Florida. In all cases, the studied populations show genetic flow. A comparison of these values with the ones obtained in our study suggests that these populations do not currently have genetic flow doing a $\chi^{2}$ test, according to Workman and Niswander (1970) and Apostol et al. (1995), where the null hypothesis is that the two species are genetically identical or that there is genetic flow between them. The number of degrees of freedom is given by $n-1$, where $n$ is the number of subpopulations. The program used to 
estimate the Fst (RAPDFST from RAPDBIOS), calculates contingent values for $\chi^{2}$ and computes probability values. In this study, probability was 0.00 and that the null hypothesis can be rejected, because the two species show no genetic flow between them.

Results obtained from the 3 ' of the $18 \mathrm{~S}$ ribosomal gene, the internal transcribed spacer 1, and the 5.8 ribosomal gene amplification presents a band of $1000 \mathrm{bp}$ and a second one of approximately 600 $\mathrm{bp}$, although the presence of the latter is not constant and the amplification may be low. The results suggest that the sylvatic and domiciliated populations of Rhodnius possess at least two distinct forms of ITS, which differ from each other in size. The reason from this heterogeneity is unclear, but may be due to the number of copies of tRNA located in the ITS region. Previous investigators have shown that one or more tRNA can be present in the 16S-26S rDNA ITS region of Escherichia coli (Lund \& Dahlberg 1977, Loughney et al. 1982). A possible insertion of this kind has also been suggested for the rDNA-ITS of Enterococci gallinarum (Tyrrell et al. 1977).

The differences are also consistent with a model in which molecular drive rapidly gives rise to the unique spacer patterns in populations, and then drives them to high frequencies (Dover 1982). Local populations acquire unique ITS patterns because molecular drive causes ITS repeats to converge among members of a population more rapidly than gene flow introduces new variants that can disrupt ITS associations. Molecular drive may have several biological consequences, since it may contribute to a mode of variation generating intrapopulation cohesion and interpopulation discontinuities that can be seen by differences in rDNA and can generate phenotype differences (Dover 1982).

The patterns seen for the present results are entirely consistent with what might be expected for population differentiation due to genetic drift and restricted gene flow. Our results suggest that gene flow, as well as genetic drift and other population level forces, may be important in determining the fate of rDNA variants.

In terms of vectorial transmission, the presence of two clearly differentiated populations implies that the sylvatic $R$. colombiensis is irrelevant in control programs that involve this type of habitat. However, the migration rate of this species to the dwellings should be periodically monitored.

\section{ACKNOWLEDGEMENTS}

To Jean Pierre Dujardin, Bruce Alexander and CJ Schofield for reviewing the manuscript and for valuable discussions.

\section{REFERENCES}

Apostol BL, Black WC IV, Miller BR, Reiter P, Beaty BJ 1993. Estimation of the number of fullsiblings family at an oviposite site using RAPD-PCR markers: applications to the mosquito Aedes aegypti. Theor Appl Genet 86: 991-1000.

Bossart JL, Scriber JM 1995. Maintenance of ecologically significant genetic variation in the tiger swallowtail butterfly through differential selection and gene flow. Evolution 49: 1163-1171.

Dover G 1982. Molecular drive: a cohesive mode of species evolution. Nature 226: 111-116.

Dujardin JP, Schofield CJ, Tybarenc M 1998. Population structure of Andean Triatoma infestans: allozyme frequencies and their epidemiological relevance. Med Vet Entomol 12: 20-29.

Dujardin JP, Chavez T, Moreno JM, Machane M, Noireau F, Schofield CJ 1999. Comparison of isoenzyme electrophoresis and morphometric analysis for phylogenetic reconstruction of the Rhodniini (Hemiptera: Reduviidae: Triatominae). J Med Entomol 36: 653-659.

Gomes ML, Macedo AM, Vago AR, Pena SD, Galvão LM, Chiari E 1998. Trypanosoma cruzi: optimization of polymerase chain reaction for detection in human blood. Exp Parasitol 88: 28-33.

Guhl F, Schofield CJ 1996. Population genetics and control of triatominae. Parasitol Today 12: 169-170.

Long JC 1986. The allelic correlation structure of Gianjand Kalam-speaking people. I. The estimation and interpretation of Wrigth's F-Statistics. Genetics 112: 629-647.

Lopez G, Moreno J 1995. Genetic variability and differentiation between populations of Rhodnius prolixus and $R$. pallescens, vectors of Chagas disease in Colombia. Mem Inst Oswaldo Cruz, 90: 353-357.

Loughney K, Lund E, Dahlberg JE 1982. tRNA genes are found between $16 \mathrm{~S}$ and $23 \mathrm{~S}$ rRNA genes in $\mathrm{Ba}$ cillus subtilis. Nucleic Acids Res 10: 1607-1624

Lund E, Dahlberg JE 1977. Spacer tranfer RNAs in transcripts of E. coli processing of $30 \mathrm{~S}$ ribosomal RNA in vitro. Cell 11: 247-262.

Lynch M, Milligan BG 1994. Analysis of population genetic structure with RAPD markers. Mol Ecol 3: 91-99.

Moreno J, Galvão C, Jurgerg J 1999. Rhodnius colombiensis sp. $n$. da Colombia com quadros comparativos entre estruturas fálicas do gênero Rhodnius Stal. 1859 (Hemiptera, Reduviidae, Triatominae). Entomol Vect 6: 601-616.

Sanguinetti CJ, Dias Neto E, Simpson AJ 1994. Rapid silver staining and recovery of PCR products separated on polyacrylamide gels. Biotechniques 17:914921.

Schmunis 1994. La enfermedad de Chagas y el sistema nervioso. OPS 547: 3-31.

Susunaga G, Monroy E, Vallejo GA 1991. Caracterización biológica de cepas de Trypanosoma cruzi aisladas en Coyaima (Departamento del Tolima). Rev Asoci Colombiana Cien Biol 5: 53-63.

Tyrrel GJ, Bethure B, Willey-Low DE 1977. Species identification of Enterococci via intergenic riboso- 
1048 Molecular Differentiation of Rhodnius - Carlos Jaramillo et al.

mal PCR. J Clin Microbiol 35: 1054-1060.

Weir BS, Cockerham CC 1984. Estimating F-statistics for the analysis of populations structure. Evolution 38: 1358-1370.

Workman PL, Niswander JD 1970. Population studies on southwestern Indian tribes. II. Local genetic differentiation in the Papago. Am J Hum Genet 22: 2449.

Wright S 1951. The genetical structure of populations. Ann Eugen 15: 323-354. 